$$
\begin{array}{r}
\text { CONF- } 960493--18 \\
\text { UCRL-JC-123007 }
\end{array}
$$

\title{
Image Degradation from Surface Scatter in EUV Optics
}

\author{
D. P. Gaines, T. P. Daly, D. G. Stearns, \\ B. LaFontaine, D. W. Sweeney, D. Fuchs

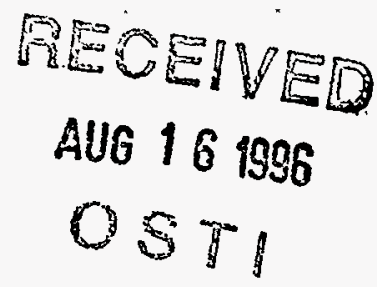 \\ This paper was prepared for submittal to the \\ Optical Society of America Extreme Ultraviolet Lithography \\ Boston, MA \\ April 29-May 3, 1996
}

May 28, 1996

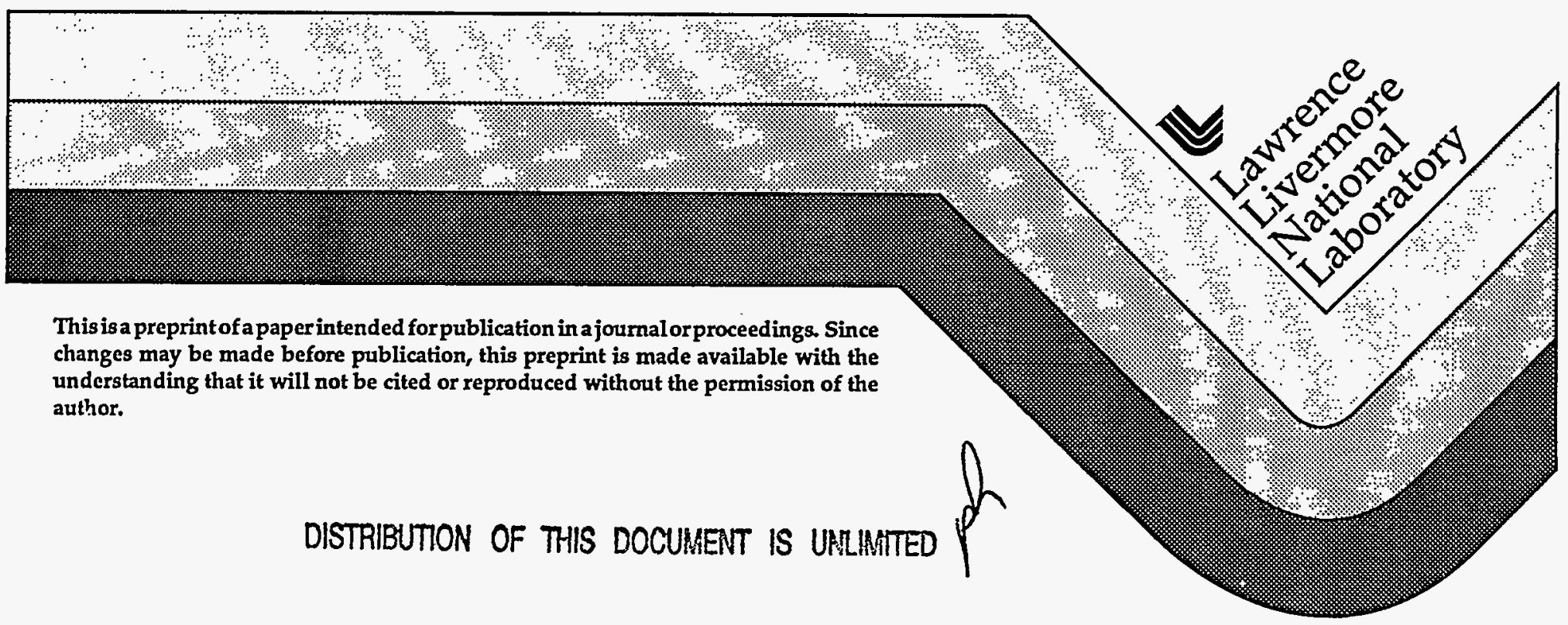

This is a preprint of a paperintended for publication in a journal or proceedings. Since changes may be made before publication, this preprint is made available with the understanding that it will not be cited or reproduced without the permission of the author.

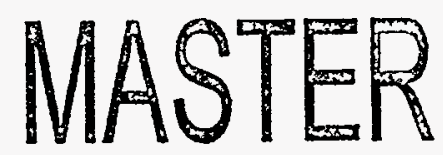




\section{DISCLAIMER}

This document was prepared as an account of work sponsored by an agency of the United States Government. Neither the United States Government nor the University of California nor any of their employees, makes any warranty, express or implied, or assumes any legal liability or responsibility for the accuracy, completeness, or usefulness of any information, apparatus, product, or process disclosed, or represents that its use would not infringe privately owned rights. Reference herein to any specific commercial product, process, or service by trade name, trademark, manufacturer, or otherwise, does not necessarily constitute or imply its endorsement, recommendation, or favoring by the United States Government or the University of California. The views and opinions of authors expressed herein do not necessarily state or reflect those of the United States Government or the University of California, and shall not be used for advertising or product endorsement purposes. 


\section{DISCLAIMER}

Portions of this document may be illegible in electronic image products. Images are produced from the best available original document. 


\title{
Image Degradation from Surface Scatter in EUV Optics
}

\author{
D. P. Gaines, T.P. Daly. D.G. Stearns, B. LaFontaine, D.W. Sweeney \\ Lawrence Livermore National Laboratory, P.O. Box 808, L-395, Livermore, CA 94551 \\ D. Fuchs \\ Physikalisch-Technische Bundesanstalt, Abbestr. 2-12, D-10587 Berlin, Germany
}

\begin{abstract}
Synchrotron-based $13 \mathrm{~nm}$ measurements of scatter from individual mirrors and an assembled imaging system for Extreme Ultraviolet Lithography have been compared to a model of image formation in the presence of scatter. The theory uses a Power Spectral Density description of the constituent optics to describe modifications to the image due to scatter. Reasonable agreement between measurements and theory was obtained for both individual mirrors and the assembled system.
\end{abstract}

Keywords: Scattering measurements, Scattering by rough surfaces, Microlithography

\section{Introduction}

Scattered light can degrade the imaging performance of projection systems used in Extreme Ultraviolet Lithography (EUVL) by reducing contrast in the aerial image. Requirements for future EUV lithographic systems will necessarily include demanding specifications on surface roughness to reduce scatter to manageable levels. These specifications will be derived from predictions of imaging performance based on models of scattering in the multi-element, all-reflective, multilayer-coated optical systems required at EUV wavelengths. The Power Spectral Density (PSD) is an important component of these theories, because the imaging performance of an optical system with rough surfaces can be described using a statistical treatment of scatter that is based upon the PSD of the constituent optics.

To date, evidence of scatter in EUVL has been inferred mainly from measurements of mirror reflectance and the limited process latitude that is observed in printing experiments, not from PSD characterizations. It is likely that future systems and optics will be qualified solely on the basis of PSD functions derived from substrate metrology. Therefore, it is important that imaging performance in the presence of scatter be correctly described by the scattering formalisms that are based upon PSD descriptions.

This paper begins the process of experimental verification of such a theory. Specifically, atwavelength scattering experiments performed at the BESSY synchrotron in Berlin, Germany, will be compared with results obtained from surface characterization measurements and a PSD-based scattering theory, described elsewhere.[1,2] In addition to measurements of scattering from concave and convex multilayer-coated mirrors, direct measurements of scattering from an assembled EUVL projection system will be presented.

\section{Scattering Model}

Coherent imaging theory was used to model the BESSY experiment and determine response functions for both individual optics and the assembled optical system. The intensity profile, in frequency space, at the image plane is given by 


$$
\begin{aligned}
& \mathbf{I}_{1}\left(f_{x}, f_{y}\right)= \\
& \int_{-\infty}^{+\infty} \int_{-\infty}^{+\infty} \mathbf{G}_{i}\left(f_{x}^{\prime}, f_{y}^{\prime}\right) G_{i}^{\prime}\left(f_{x}^{\prime}-f_{x}, f_{y}^{\prime}-f_{y}\right) d f_{x}^{\prime} d f_{y}^{\prime} .
\end{aligned}
$$

where $\mathbf{G}_{i}\left(f_{x} f_{y}\right)$ is the fourier transform of the field amplitude at the image plane. The effect of scatter is included by introducing a phase modulation, $\mathrm{W}(x, y)$, in the transform of the amplitude impulse response function $\mathbf{H}\left(f_{x} f_{y}\right)$. [3]

$$
\begin{aligned}
& \mathbf{G}_{i}\left(f_{x}, f_{y}\right)=\mathbf{H}\left(f_{x}, f_{y}\right) \mathbf{G}_{s}\left(f_{x}, f_{y}\right) \\
& \mathbf{H}\left(f_{x}, f_{y}\right)=\left.\mathbf{P}(x, y) \exp \left(\frac{2 \pi i \mathrm{~W}(x, y)}{\lambda}\right)\right|_{x=\lambda d f_{x}, y=\lambda d f_{y}}
\end{aligned}
$$

$\mathbf{P}(x, y)$ is the complex pupil function, $\mathbf{G}_{8}\left(f_{x} f_{y}\right)$ is the fourier transform of the geometrical image, and $d$ is the distance from the mirror to the image, or in the case of an optical system, the distance from the exit pupil to the image. By taking the ensemble average of the transformed image and assuming stationarity, the convolution theorem may be used to obtain

$$
\begin{aligned}
& \mathbf{I}_{i}(x, y)= \\
& \int_{-\infty}^{+\infty} \int_{-\infty}^{+} I_{\text {wos }}(\varepsilon, \eta) \operatorname{PSF}_{\text {scat }}(x-\varepsilon, y-\eta) d \varepsilon d \eta
\end{aligned}
$$

where $I_{\text {wos }}(x, y)$ is the image intensity obtained for perfectly smooth mirrors that do not scatter radiation, and $\operatorname{PSF}_{\text {scor }}(x, y)$ is a function, similar to a point spread function, that is dependent upon the scattering properties of the substrate(s). In the smooth surface

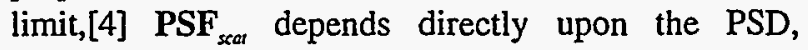
otherwise, it depends upon the fourier transform of the PSD, or autocovariance of the surface. In an optical

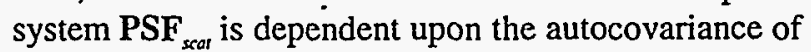
the exit pupil.[5]

The BESSY measurements integrate the signal transmitted through a slit. The signal $\mathbf{s}(x)$ can be represented as

$$
\begin{aligned}
\mathrm{s}(\mathrm{x}) & =\int_{-\infty}^{+\infty} \mathrm{T}\left(x-x^{\prime}\right) d x^{\prime} \int_{-\infty}^{+\infty} \mathbf{I}_{i}\left(x^{\prime}, y^{\prime}\right) d y^{\prime} \\
& =\int_{-\infty}^{+\infty} \mathbf{s}_{\text {uiss }}(\varepsilon) \mathrm{LSF}_{\text {sctr }}(x-\varepsilon) d \varepsilon
\end{aligned}
$$

where $\mathbf{T}(x)$ is the transmission function of the slit, $\mathbf{s}_{\text {wos }}(x)$ is the signal at the detector in the absence of scatter, and $\operatorname{LSF}_{\text {seas }}(x)$ is a line spread function that depends upon the scattering properties of the surface(s).

\section{Experiment}

Multilayer-coated optics fabricated for the projection system of the Lawrence Livermore National Laboratory (LLNL) EUV lithography station were characterized both individually, and as an assembled system, at the Physikalisch-Technische Bundesanstalt (PTB) $x$-ray metrology beamline at the BESSY synchrotron in Berlin, Germany.[6,7] The LLNL projection system[8] consists of two mirrors, one concave and one convex, which are utilized in a fourbounce arrangement, shown in Fig. 1. The individual mirrors are $75 \mathrm{~mm}$ in diameter, with radii of curvature of $137 \mathrm{~mm}$.

For incidence angles of $6^{\circ}$, the multilayer coatings reflect at $13.15 \mathrm{~nm}$ for the concave optic, and 13.20 $\mathrm{nm}$ for the convex optic.

The angular distribution of reflected radiation was measured by scanning a $400 \mu \mathrm{m} \times 8 \mathrm{~mm}$ slit through the reflected beam. The sample to detector distance was $90 \mathrm{~mm}$ for the convex optic, and $150 \mathrm{~mm}$ for the concave optic. For measurements of the assembled system, the detector slit was $600 \mu \mathrm{m} \times 8 \mathrm{~mm}$, and the

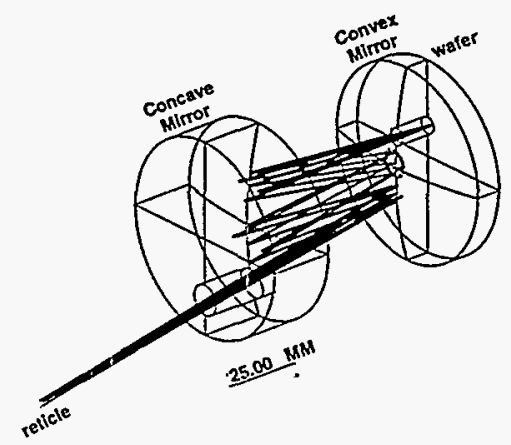

Figure I. LLNL EUVL two-mirror four-bounce projection system. 
distance from the midpoint between mirrors to the detector was $230 \mathrm{~mm}$. For the system measurements, the incoming beam had a divergence of $0.08 \mathrm{mrad}$. The object side NA of the imager was 0.019. The detector was a Channel Electron Multiplier operated in the pulse counting mode. The angular step size was $0.021^{\circ}$. The total range of travel was $\pm 1^{\circ}$.

Because the actual imaging mirrors were not accessible, the PSD of a sister mirror to the LLNL convex optic was characterized. A Digital Instruments Dimension 5000 Atomic Force Microscope (AFM) and a Zygo NewView 100 white-light interferometric microscope was used to obtain the PSD of the sister mirror. This PSD was taken to be representative of surfaces in the actual imaging system.

\section{Results and Discussion}

The image without scatter, $I_{\text {wos }}(x, y)$, was determined by calculating the intensity pattern at the conjugate of the detector plane using scalar diffraction theory and the geometry of the beamline monochromator and reflectometer. The line spread function due to scatter, $\mathbf{L S F}_{\text {sca }}(x)$, was calculated for the both individual mirrors and for the entire system using the PSD from a sister mirror to the convex optic. The PSD data is presented elsewhere.[9]

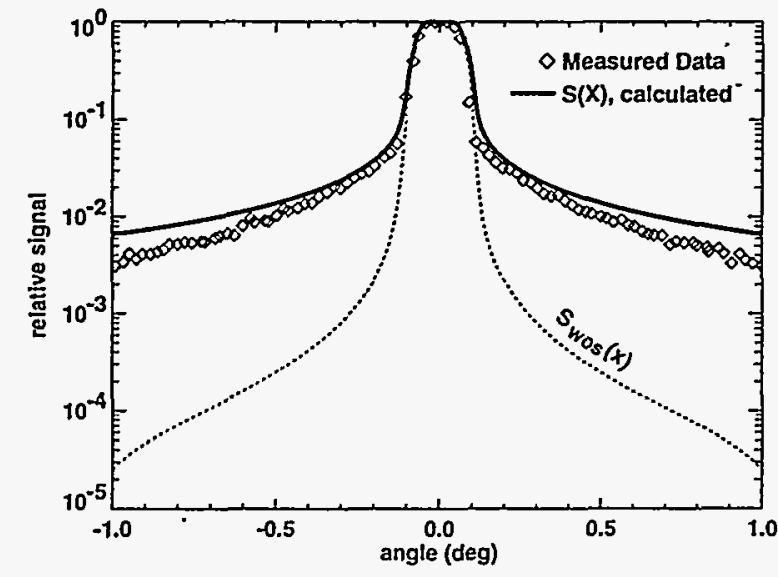

Figure 2. Calculated signal without scatter, calculated signal with scatter, and measured signal for LLNL concave imaging mirror.
The signal with scatter, $\mathrm{s}(x)$, was computed for the individual concave and convex mirrors. Fig. 2. shows the calculated signal without scatter, $\mathrm{s}_{\text {wos }}(x)$, the calculated signal with scatter, $\mathrm{s}(x)$, and the measured signal for the concave mirror. Fig. 3. shows similar data for the convex mirror.

The scattering model overestimates scattering and the resulting detector signal at the extremes of the angular scan $\left( \pm 1^{\circ}\right)$ for the concave mirror. The worst case value is a factor of $2 \mathrm{X}$ in signal level at $-1^{\circ}$. This result is expected to improve once the PSD from the actual surface is determined.

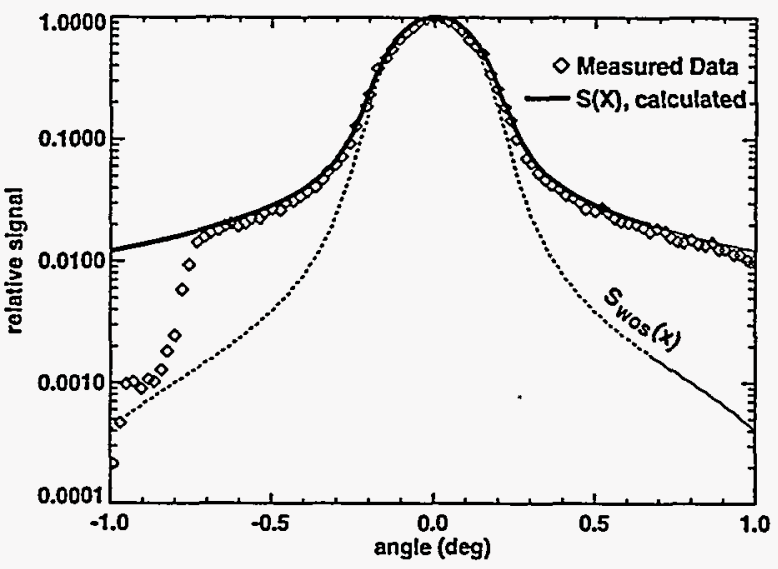

Figure 3. Calculated signal without scatter, calculated signal with scatter, and measured signal for LLNL convex imaging mirror.

The model accurately predicts the form of scattering from the convex optic, which is a reasonable result because the PSD is based on measurements of a sister optic. The rapid decrease in signal level at angles less than $-0.7^{\circ}$ occurs because the detector package moved into the incoming beam.

The system measurements and model predictions are shown in Fig. 4. The model was not successful in predicting the exact form of the scattering, but the relative levels between the peak and wings were correct. Again, it is expected that the match between theory and measurements will improve once PSDs have been calculated for the actual surfaces. 


\section{Conclusions}

A multi-element scattering model that uses PSD functions from the constituent optics to describe image formation in the presence of scatter has been successfully used to model the results of an atwavelength, synchrotron-based, interrogation of scatter from individual optics, and from an assembled EUV projection system. Future improvements in theoretical predictions are expected as the surfaces in the imaging system are fully characterized.

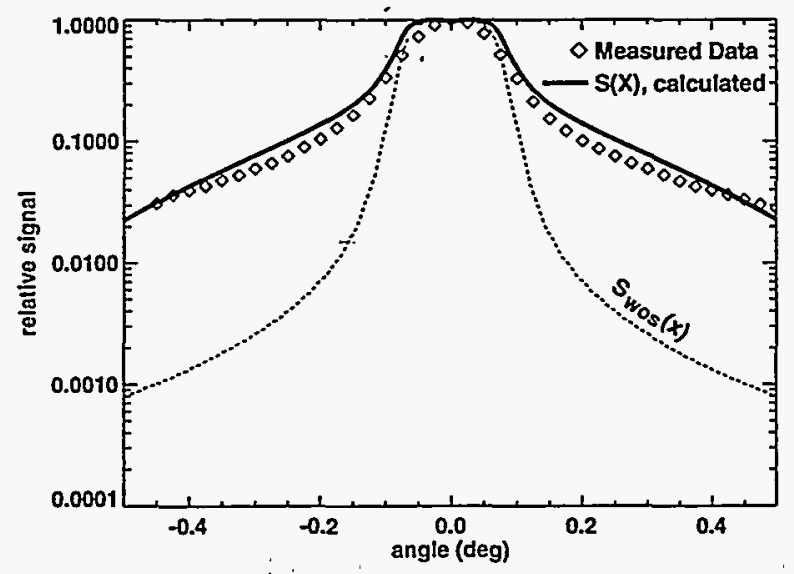

Figure 4. Calculated signal without scatter, calculated signal with scatter, and measured signal for the LLNL assembled two-mirror, four-bounce imaging system.

\section{References and Notes}

1. T. Daly, "The effect of scattering in the imaging optics", internal memo, Advanced Microtechnology Program, Lawrence Livermore National Laboratory, 20 Jan 1995.

2. D.G. Stearns, D.P. Gaines, B. LaFontaine, G.E. Sommargren, D.W. Sweeney, D.R. Kania, and N.M. Ceglio, "Nonspecular Scattering in EUV Lithography: Determining Specifications for Surface Finish," presented at The Optical Society of America Topical Meeting on Extreme Ultraviolet Lithography, Boston, Massachusetts, 1-3 May, 1996.
3. This form is valid if the amplitude of the pupil function is not modified by scatter.

4. The smooth surface limit is the condition where $k^{2} \sigma^{2} \ll 1$, where $\mathrm{k}$ is the magnitude of the wavevector, and $\sigma$ is the rms roughness.

5. For the telecentric systems used in EUVL, the exit pupil is at infinity, and the analysis must be suitably modified to describe an alternate surface which, when transformed, yields the correct image. This modification causes a field dependency to occur in the formulation.

6. D. Fuchs, M. Krumrey, T. Lederer, P. Müller, F. Scholze, G. Ulm, "Soft X-ray reflectometer for large and complex samples using synchrotron radiation", Proc. Soc. Photo-Opt. Instrum. Eng. 2279, (1994)

7. David P. Gaines, Stephen P. Vernon, and Gary. E. Sommargren, "EUV Characterization of a FourBounce Projection System," OSA proceedings on Extreme Ultraviolet Lithography, Frits Zernike and David T. Attwood, eds. (Optical Society of America, Washington, DC 1995), Vol 23, pp. 171176.

8. G.E. Sommargren, "Performance of a Two Mirror, Four Reflection, Ring Field Imaging System," OSA proceedings on Extreme Ultraviolet Lithography, Frits Zernike and David T. Attwood, eds. (Optical Society of America, Washington, DC 1995), Vol 23, pp. 103-108.

9. D.P. Gaines, D.W. Sweeney, K.W. DeLong, S.P. Vernon, S.L. Baker, D.A. Tichenor, R. Kestner, "Surface Characterization of Optics for EUV Lithography," these proceedings.

This work was performed under the auspices of the U.S. Department of Energy by Lawrence Livermore National Laborátory under contract No. W-7405Eng-48. 